\title{
Research on Characteristic Stress and Constitutive Equation of Confined Sandstone during Damage Evolution Based on Energy Evolution Analysis
}

\author{
Xiaobin Yang $\mathbb{D}^{1},{ }^{1}$ Hongming Cheng $\mathbb{D},{ }^{1,2}$ Xin Hou, ${ }^{1}$ Chaogang Nie, ${ }^{1}$ and Jiaqi Lv ${ }^{1}$ \\ ${ }^{1}$ School of Emergency Management and Safety Engineering, China University of Mining and Technology, Beijing 100083, China \\ ${ }^{2}$ School of Coal Engineering, Shanxi Datong University, Datong 037003, China \\ Correspondence should be addressed to Hongming Cheng; cheng126121@163.com
}

Received 3 April 2019; Revised 3 June 2019; Accepted 24 June 2019; Published 7 July 2019

Guest Editor: Dariusz Rozumek

Copyright ( 2019 Xiaobin Yang et al. This is an open access article distributed under the Creative Commons Attribution License, which permits unrestricted use, distribution, and reproduction in any medium, provided the original work is properly cited.

\begin{abstract}
This study implements the cyclic loading-unloading triaxial compression tests with confining pressures of 5, 10, 20, and $30 \mathrm{MPa}$ for determining the characteristic stress and constitutive equation of sandstone during damage evolution. The energy evolution characteristics and transformations are analyzed, the energy proportion evolution law is defined and analyzed, and its process is divided into five stages according to the whole stress-strain curve. Then, the dissipation energy proportion method for determining the characteristic stress is proposed and compared with the lateral strain method and the volumetric strain method, and the differences of characteristic stress determined by the three methods are within the acceptable error range, i.e., the proportion of crack initiation stress and crack damage stress to peak stress are all about $40 \%$ and $70 \%$, respectively, and least affected by the confining pressures. The new method has strong maneuverability, clearer response to the damage evolution, better coordination with the damage evolution, and less subjective initiative. In addition, the dissipation energy proportion behavior is captured by fitting function and established a relationship with elastic modulus of sandstone, and then the damage evolution constitutive equation of sandstone is established based on energy proportion. Finally, the theoretical curve and experimental curve of damage evolution are compared according to the five stages of dissipation energy proportion evolution, and the result shows that the damage evolution constitutive equation is reasonable.
\end{abstract}

\section{Introduction}

The stability of geotechnical engineering depends on the physical and mechanical environment in which rock materials are located and their mechanical behavior. As a heterogeneous natural geological material with internal microstructure (joints, cracks, inclusions, etc.), the study of the damage evolution process of rock materials has important guiding significance for the design, construction, and operation stability evaluation of geotechnical engineering. At present, laboratory tests of rock materials generally show that the damage evolution process of loaded rock specimens has experienced crack closure, crack initiation, crack penetration, and crack coalescence [1-3]. According to the damage evolution state of rock samples, many scholars divide the whole stress-strain curve into five important stages, including the crack closure stage, linearelastic deformation stage, stable crack growth stage, unstable crack growth stage, and postpeak damage stage. Corresponding to the five stages of damage evolution, the characteristic stress and crack evolution laws in each stage are given, namely, the crack closure stress $\left(\sigma_{\mathrm{cc}}\right)$, the crack initiation stress $\left(\sigma_{\mathrm{ci}}\right)$, the crack damage stress $\left(\sigma_{\mathrm{cd}}\right)$, the peak stress $\left(\sigma_{\mathrm{p}}\right)$, and the residual stress $\left(\sigma_{\mathrm{c}}\right)$ [4-8]; in particular, the $\sigma_{\mathrm{ci}}$ and $\sigma_{\mathrm{cd}}$ can guide geotechnical engineering design, construction, and operation stability evaluation. Hoek and Brown [9] found that when the far-field maximum stress magnitude exceeded 0.15 of the UCS, spalling was observed around the underground opening of square tunnels in South Africa. Martin and Christiansson [10] and Andersson et al. [11] voted that the $\sigma_{\mathrm{ci}}$ determined by uniaxial compressive tests could be used as an estimate for the in situ spalling 
strength, while the ISRM makes no mention of the method for determining characteristic stress in its "Suggested methods for determining the uniaxial compressive strength and deformability of rock materials." Thus, finding a reliable method for determining characteristic stress may be beneficial to geotechnical engineering when estimating the damage evolution state.

To better estimate characteristic stress, various scholars have proposed different methods based on unconfined and confined laboratory tests. Brace et al. [4] utilized the volumetric strain-axial strain curve to determine the $\sigma_{\mathrm{ci}}$; they noted that the volumetric strain presented linear characteristics before the $\sigma_{\mathrm{ci}}$, while it presented nonlinear characteristics after the $\sigma_{\mathrm{ci}}$, so the point deviated from the linear portion was the $\sigma_{\mathrm{ci}}$. Considering initial cracks of rock materials, Martin and Chandler [5] proposed that using the crack volumetric strain-axial strain curve determined the $\sigma_{\mathrm{ci}}$; they noted that the curve had a horizontal section with a value of zero, the onset of the horizontal section was the $\sigma_{\mathrm{cc}}$, and the end was the $\sigma_{\mathrm{ci}}$. It is well known that the lateral strain is more sensitive than the axial strain, for the lateral dilatancy of rock samples at the stable crack growth stage. Consequently, Lajtai [12] drew a tangent line on the curve of axial stress-lateral strain, and the point where the lateral strain deviated from linearity was the $\sigma_{\text {ci }}$. Nicksiar and Martin [13] proposed the lateral strain response method; firstly, using the volumetric strain method determined the $\sigma_{\mathrm{cd}}$ and connected the value of lateral strain corresponding the $\sigma_{\mathrm{cd}}$ to the original point as a reference line; then, the difference between lateral strain and reference line was captured and drawn vs axial stress, and the maximum value point on the curve was the $\sigma_{\mathrm{ci}}$. Latterly, with the application of acoustic emission in monitoring the damage evolution of loaded rock specimens, it is feasible that acoustic emission reveals the phenomenon of crack at different stages of damage deformation. Eberhardt et al. [14], Zhao et al. [15], and Xue et al. [16] drew a tangent line on the AE count-axial stress curve, and the point where the AE count deviated from linearity was the $\sigma_{\mathrm{ci}}$. In practical applications, some of these methods feebly respond to the crack evolution and more or less have subjectivity, such as determining the linear segment by using the lateral strain method and $\mathrm{AE}$ method. In addition, the change of index of these methods is not in coordination with the damage evolution, which cannot reflect all characteristic stress in the whole stress-strain curve, such as the volumetric strain method only determining the $\sigma_{\mathrm{cd}}$, and the $\sigma_{\mathrm{cd}}$ should be determined firstly by the volumetric strain method when using the lateral strain response method [17-19]. To divide the process of damage evolution more intuitively and determine characteristic stress more accurately, it is urgent to find new parameters and propose new methods.

In nature, a series of physical changes during loading rock specimens, such as crack closure, initiation, growth, and coalescence, are energy transformation, i.e., the damage of loaded rock specimens going through energy absorption, accumulation, dissipation, and release. Xie et al. [20, 21] considered that the deformation and damage of rock were a process of exchanging material and energy with the outside and delineated inner relation between deformation damage and energy dissipation/release. Zhang and Gao [22] determined the elastic strain energy (ESE) and dissipation energy (DE) evolution and distribution through energy tests for red sandstone under uniaxial compression. Deng et al. [23] designed uniaxial cyclic loading tests and explored the parameter variation and interrelation, such as the total absorption energy (TAE), the ESE, and the DE. Meng et al. [24] explored the character of energy accumulation and dissipation during deformation and damage of rock specimens under various loading and unloading schemes and revealed the energy accumulation and dissipation evolution and distribution at the prepeak stage. Under the current scope of work, a unified understanding of energy transformation during loading has been obtained: the TAE transforms into the ESE and the DE, and more absorption energy transforms into the ESE which is stored in rock specimens than the DE at the prepeak stage, while the DE increases and the ESE dissipates rapidly at the postpeak stage. In contrast, few articles care about energy transformation corresponding to the physical change of crack closure, initiation, growth, and coalescence during loading rock specimens. Whether the key points of energy evolution associate with the characteristic stress in damage evolution or not, whether the energy evolution relates to the material parameter evolution of rock specimens or not, and whether the constitutive equation of rock is established from the energy evolution point of view or not have not been explored in depth.

Based on this fact, this paper designed the cyclic loadingunloading triaxial compression tests, introduced the energy proportion, proposed a new method to research crack closure, initiation, growth, and coalescence of loaded rock specimens, and established and verified the constitutive equation from the point of view of energy evolution.

\section{Experimental}

2.1. Rock Specimen Preparation. The experimental specimens were sandstone, all machined from the same sandstone block, exhibiting fine consistency and integrity with no obvious joints and cracks, and were carefully produced standard specimens with $50 \mathrm{~mm}$ in diameter and $100 \mathrm{~mm}$ in height and were ground to produce flat parallel surfaces with $\pm 0.02 \mathrm{~mm}$ parallelism (see Figure 1 ) according to the ISRMsuggested method.

2.2. Test Equipment and Procedure. We implemented conventional triaxial compression tests and cyclic loadingunloading triaxial compression tests with the RLJW-2000 triaxial shear-creep testing system (see Figure 2(a)), with $2000 \mathrm{kN}$ maximum axial loading capacity and $50 \mathrm{MPa}$ maximum confining pressure. Axial and lateral displacement data were collected by extensometers (see Figure 2(b)).

Firstly, the conventional triaxial compression tests were implemented with confining pressures of 5, 10, 20, and $30 \mathrm{MPa}$, and the triaxial compressive strength (TCS) was scored. Then, the cyclic loading-unloading triaxial compression tests were implemented with confining pressures of 5, 10, 20, and $30 \mathrm{MPa}$ (1) First, the specimens were wrapped 


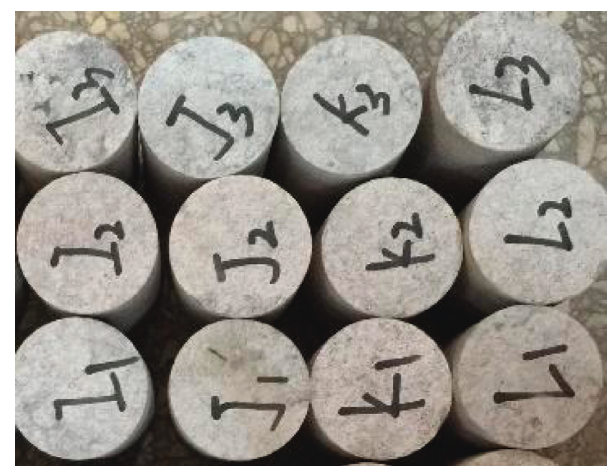

Figure 1: Sandstone specimens.

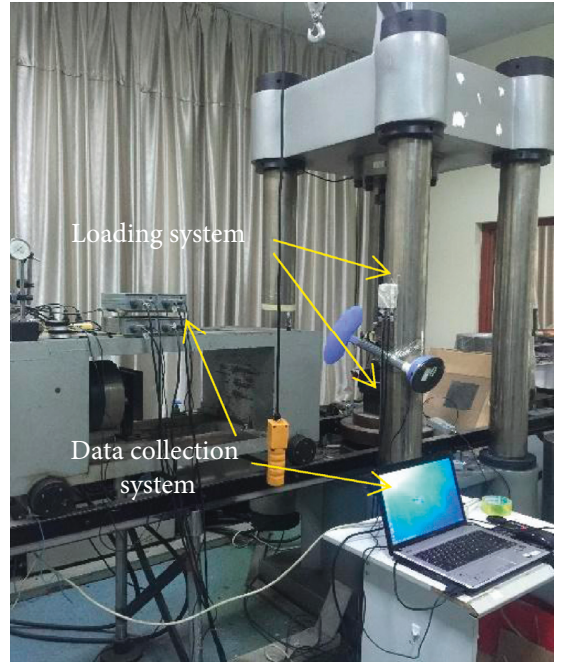

(a)

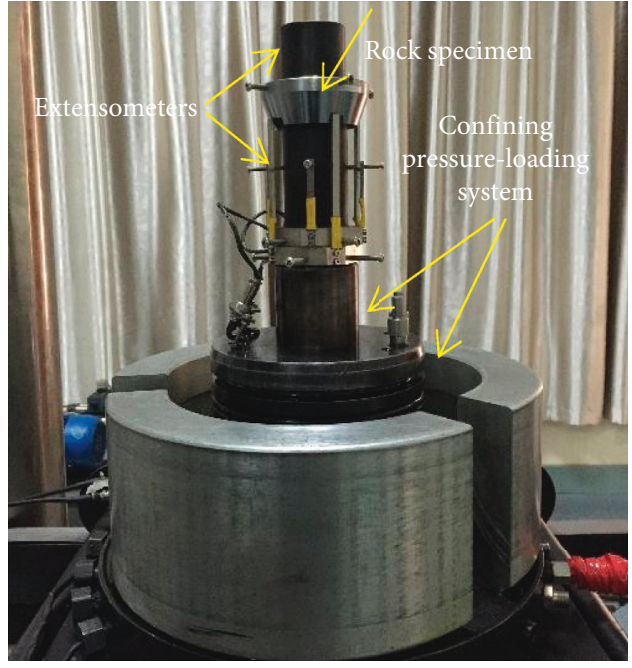

(b)

Figure 2: Test equipment. (a) Rock triaxial testing system. (b) Extensometers.

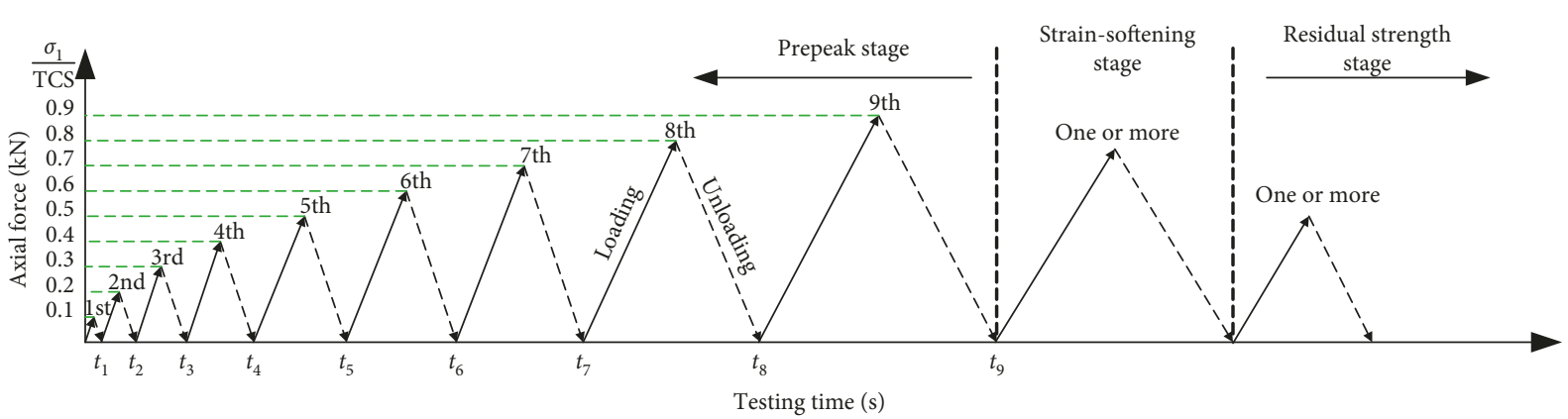

Figure 3: Experimental loading-unloading path.

up with plastic film to prevent pressure fluid entry. (2) When testing, specimens were fixed by loading small axial stress and then confining pressure was loaded to a specified value; afterwards, axial stress was loaded to a specified value at a displacement rate of $0.005 \mathrm{~mm} / \mathrm{s}$; finally, axial stress was unloaded to zero at a displacement rate of $0.005 \mathrm{~mm} / \mathrm{s}$ with constant confining pressure; the load and unload process was done repeatedly until the test ended. (3) At the prepeak stage, the unloading points were chosen which normalized to TCS (by the conventional triaxial compression tests) varying from $0.1,0.2,0.3,0.4,0.5,0.6,0.7,0.8$, to 0.9 ; at the strain-softening stage and residual strength stage, one or more loading-unloading tests were implemented, respectively (see Figure 3). 


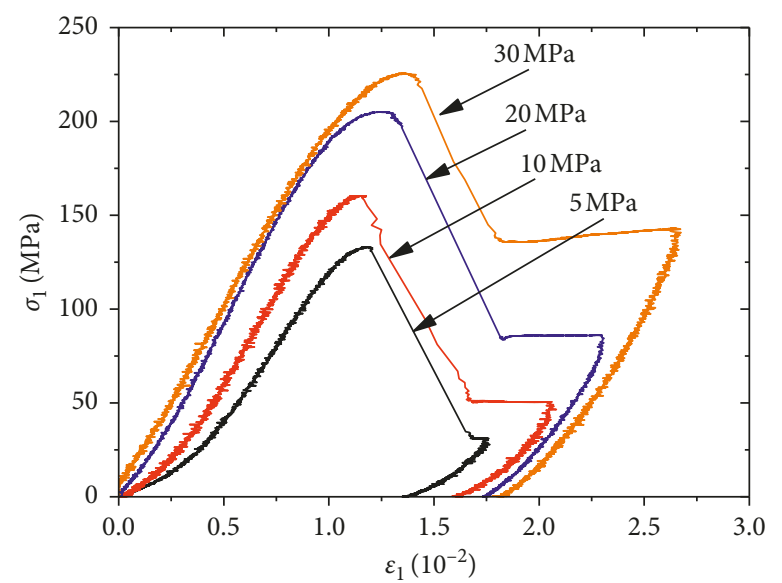

(a)

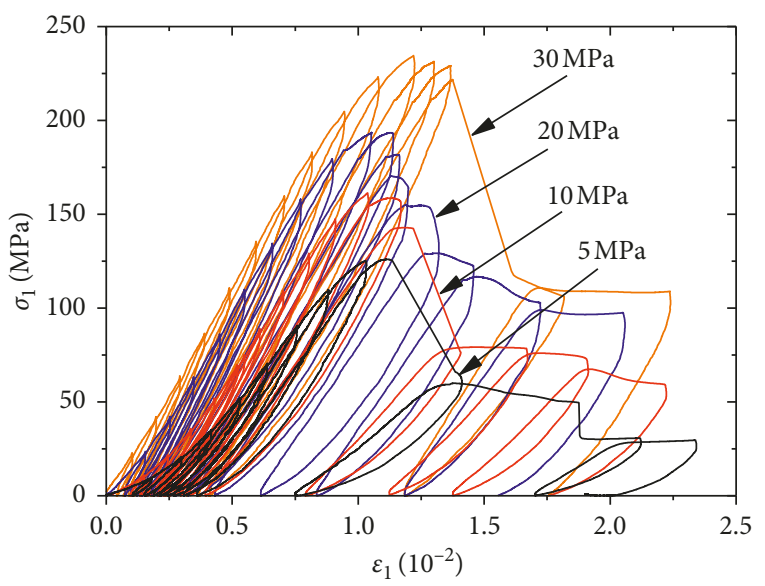

(b)

Figure 4: The axial stress-strain curves from (a) conventional triaxial compression tests and (b) cyclic loading-unloading triaxial compression tests.

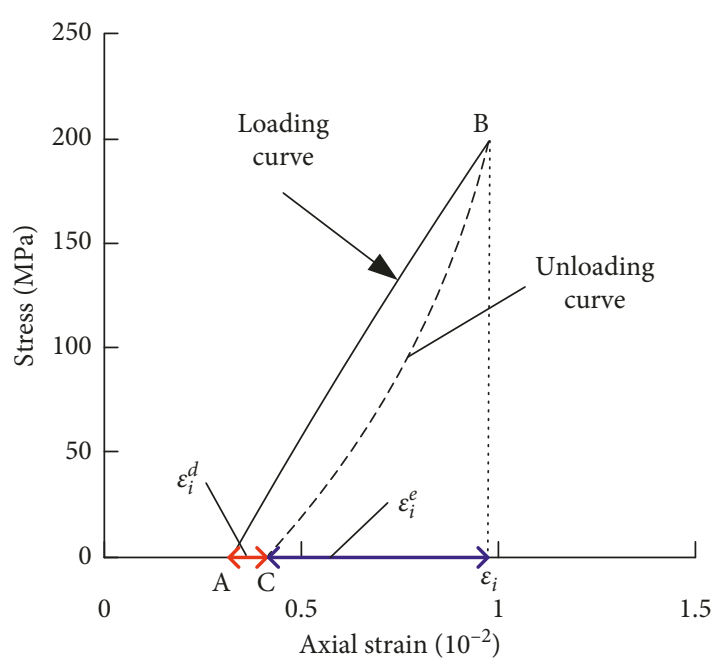

Figure 5: Relationship among the TAE, the ESE, and the DE during the $i$-th loading-unloading.

\section{Experimental Results and Analysis}

The axial stress-strain curves during conventional triaxial compression tests are shown in Figure 4(a). Two experimental groups were performed at each confining pressure during the cyclic loading-unloading triaxial compression tests. As the limitation of this article, we only showed one experimental group at each confining pressure in Figure 4(b).

We analyzed energy evolution of rock specimens based on test data. Considering the heterogeneity of rock specimens and differences between rock specimens, some simplifications were made when calculating energy for single-rock specimens: (1) neglecting the strain energy stored in rock by hydrostatic pressure working; (2) calculating the elastic modulus of a single cycle by using secant modulus, i.e., connecting the maximum stress point with the minimum stress point on a single cyclic stress-strain curve [25]; and (3) calculating the TAE and the ESE of a single cycle by the integral method (see Figure 5).
3.1. Energy Density Evolution Analysis. Energy is the driving force for internal defect evolution and propagation in rock materials $[20,21]$. At each stage of deformation of loaded rock specimens, the energy transformation is in progress $[26,27]$. During the triaxial stress state, the loaded rock specimens were taken as a closed-loop system with the supposition that no thermal transmission occurred between the rock specimen and the external environment [28]. According to the first law of thermodynamics, the TAE per unit volume of the rock specimen could be described as [28]

$$
W=\int \sigma_{1} d \varepsilon_{1}+2 \int \sigma_{3} d \varepsilon_{3}
$$

where $\sigma_{1}$ and $\varepsilon_{1}$ are the axial stress and strain, respectively, and $\sigma_{3}$ and $\varepsilon_{3}$ are the lateral stress and strain, respectively.

Taking the $i$-th time loading-unloading stress-strain curve as an example (see Figure 5), the relationship among the TAE, the ESE, and the DE was explained. As shown in Figure 5, the loading curve $\mathrm{AB}$ was higher than the unloading curve $\mathrm{BC}$; the total deformation $\left(\varepsilon_{i}\right)$ of rock caused during loading contained recoverable deformation $\left(\varepsilon_{i}^{e}\right)$ which was released at the unloading stage and irrecoverable deformation $\left(\varepsilon_{i}^{d}\right)$ used for rock damage and plastic strain. From the energy perspective, the TAE was the area under the loading curve $A B$ and the ESE was the area under the unloading curve $\mathrm{BC}$, and the difference of the above two energies was the DE:

$$
\begin{aligned}
W_{i} & =\int_{0}^{\varepsilon_{i}} \sigma d \varepsilon \\
W_{i}^{e} & =\int_{0}^{\varepsilon_{i}^{e}} \sigma d \varepsilon, \\
W_{i}^{d} & =W_{i}-W_{i}^{e}=\int_{0}^{\varepsilon_{i}} \sigma d \varepsilon-\int_{0}^{\varepsilon_{i}^{e}} \sigma d \varepsilon,
\end{aligned}
$$

where $W_{i}, W_{i}^{e}$, and $W_{i}^{d}$ are the TAE, the ESE, and the DE during the $i$-th loading-unloading, respectively.

On the axial stress-strain curves during the cyclic loading-unloading triaxial compression tests, the TAE- 


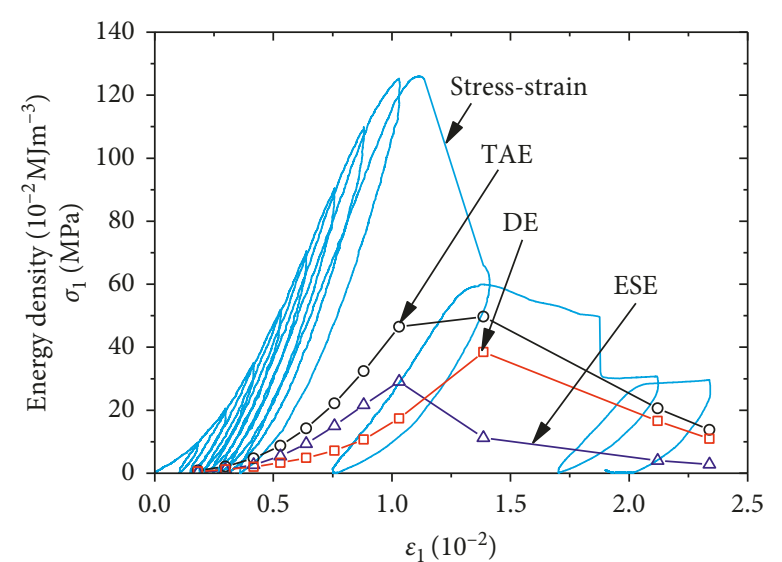

(a)

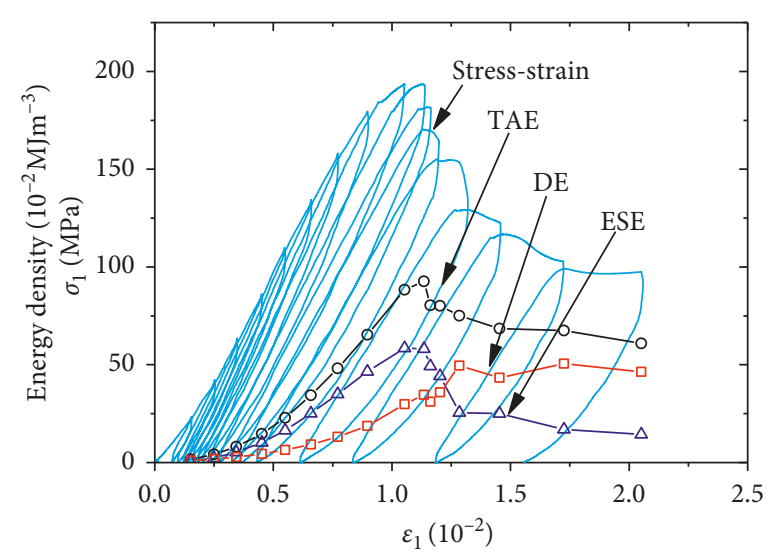

(c)

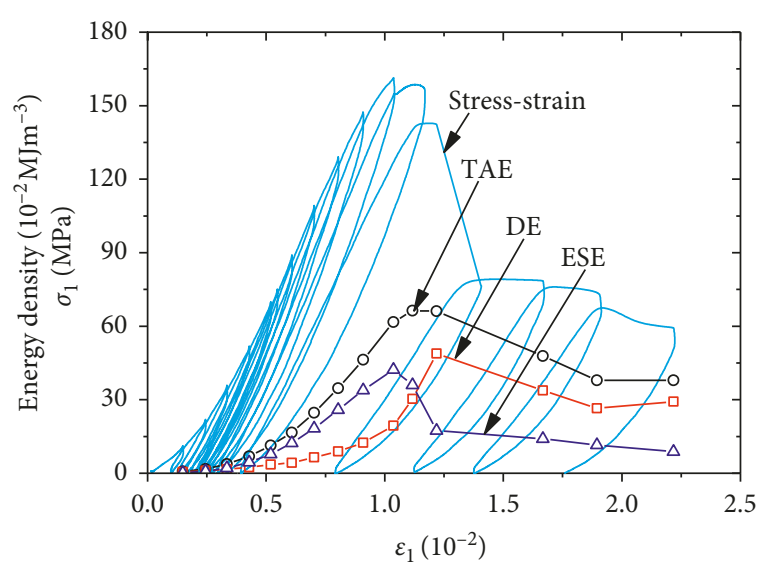

(b)

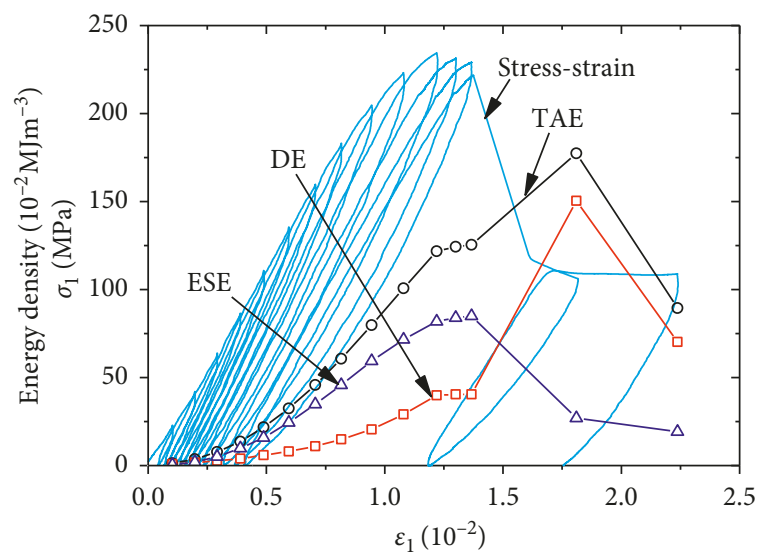

(d)

FIGURE 6: Energy evolution curves during the cyclic loading-unloading triaxial compression tests with confining pressures of $5 \mathrm{MPa}$ (a), $10 \mathrm{MPa}$ (b), $20 \mathrm{MPa}$ (c), and $30 \mathrm{MPa}(\mathrm{d})$.

strain curves, the ESE-strain curves, and the DE-strain curves were drawn, as shown in Figure 6:

(1) At the prepeak stage of the same rock specimens, the deformation changed from nonlinearity to linearity and then to nonlinearity with the increase of the number of cycles, corresponding to the crack closing first and then growing stably and finally growing unstably till macroscopic damage. At the postpeak damage stage, due to the confining pressure, the rock specimen still had carrying capacity. With the increase of confining pressure, the degree of nonlinear deformation at the stage of crack closure slowed down gradually, the TCS of rock specimens increased, and the residual strength also increased; that is, the carrying capacity increased when rock specimens were damaged.

(2) At the prepeak stage, the TAE, the ESE, and the DE increased with the axial strain increase; basically, the TAE and the ESE reached a maximum value. After the peak point, i.e., the initial postpeak damage stage, the ESE which was stored in the rock specimens at the prepeak stage dropped rapidly and converted into the DE for the macroscopic crack growth, coalescence, and caving damage of rock specimens, and the DE reached the maximum value. At the residual strength stage, the energy decreased and finally leveled off with no new damage. On the whole, with the confining pressure increase, the TAE, the ESE, and the DE increased during a single cyclic loading-unloading.

(3) Taken as a whole, the TAE, the ESE, and the DE displayed nonlinearity at the crack closure stage, while the degree of nonlinearity gradually slowed down with the confining pressure increase, corresponding to the change of stress; at the linear-elastic deformation stage and the stable crack growth stage, the three kinds of energies represented a continuous linear increase, while displayed nonlinearity at the unstable crack growth stage; the ESE and the DE changed suddenly at the initial postpeak damage stage.

3.2. Material Parameter Evolution Analysis. We calculated the elastic modulus of a single cycle at each confining pressure and drew elastic modulus-strain curves during cyclic loading-unloading, as shown in Figure 7.

Taken as a whole, the elastic modulus rose with the confining pressure increase. Under the same confining pressure, the initial elastic modulus rose, whereas the rate 


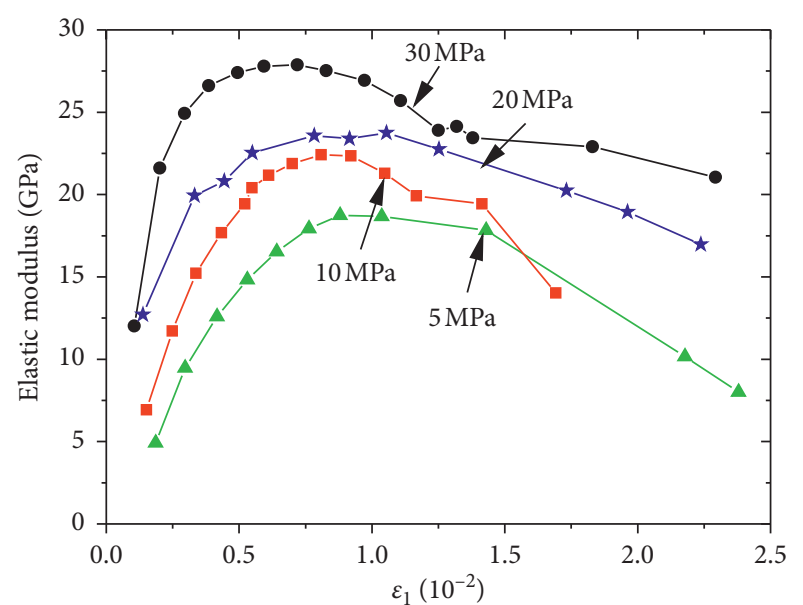

Figure 7: Elastic modulus-strain curves during cyclic loadingunloading.

of rise gradually decreased and then underwent a period of approximately linear increase and reached the maximum value, corresponding to the crack closure stage, the linearelastic deformation stage, and the stable crack growth stage, respectively. The stable crack closing and growth prompted the ESE to be stored in the rock specimens; that is, the elasticity of rock specimens was enhanced, and the maximum values of the elastic modulus with confining pressures of $5,10,20$, and $30 \mathrm{MPa}$ were $16,22,24$, and $28 \mathrm{GPa}$, respectively. During the unstable crack growth stage, the elastic modulus gradually decreased with the ESE release. The elastic modulus decreased suddenly at the initial postpeak damage stage and then gradually decreased with no new damage.

\section{Proposed Method for Determining Characteristic Stress}

As previously mentioned, the loaded rock specimens went through energy absorption, accumulation, dissipation, and release. The ESE was accumulated firstly and then released when the rock specimens damaged, while the DE which existed in the whole loading process was used for original crack closure and new crack initiation, growth, and coalescence. So, the proportion of ESE or DE in TAE reflected the relation of energy transformation during loading. Especially under some stress or strain levels, the proportion of DE in TAE could explain the condition of damage development and plastic deformation of rock specimens which directly affected rock material parameters $[29,30]$. Therefore, we defined the parameter of energy proportion, i.e., the ESE proportion $(\gamma)$ and the DE proportion $(\eta)$, and analyzed their evolution law; then, a new method for determining the characteristic stress in damage evolution was proposed based on DE proportion, and it was applied and verified finally.

4.1. Definition of Energy Proportion. We defined the parameter of energy proportion, which was taken as the proportion of ESE and DE in TAE. The ESE proportion of the $i$-th loading-unloading could be described as

$$
\gamma_{i}=\frac{W_{i}^{e}}{W_{i}}
$$

and the DE proportion of the $i$-th loading-unloading could be described as

$$
\eta_{i}=1-\gamma_{i}=1-\frac{W_{i}^{e}}{W_{i}} .
$$

On the axial stress-strain curves during the cyclic loading-unloading triaxial compression tests, we drew energy proportion-strain curves (see Figure 8).

4.2. Energy Proportion Evolution Analysis. As shown in Figure 8 , under the confining pressures of $5,10,20$, and $30 \mathrm{MPa}$, the ESE proportion increased, while the DE proportion deceased at the initial stage, but most of the TAE transformed into the DE for original crack closing, corresponding to the crack closure stage on the axial stressstrain curves; at the later crack closure stage, two kinds of energy proportion were equal. When the loaded rock specimens came into the stage of linear-elastic deformation, the ESE played an important role; contrary to the DE proportion evolution, the ESE proportion increased, while the evolution rate of two kinds of energy proportion gradually decreased. With loading, the evolution rate was gradually steady, and the ESE proportion and the DE proportion approximately linearly developed; that is, the energy transformation developed steadily, and the loaded rock specimens stayed at the stable crack growth stage. When the evolution rate was zero, the ESE proportion reached the maximum value and the DE proportion reached the minimum value in the meanwhile. When the loading stress exceeded the crack damage stress of rock specimens, the rock specimens came into the unstable crack growth stage, and the crack growth consumed energy and caused the DE proportion increase and the ESE proportion decrease, while the evolution rate gradually increased. When the loading stress exceeded the peak stress, the evolution rate suddenly increased, the DE proportion reached the peak value and finally leveled off, and the ESE proportion evolution was opposite.

Taken as a whole, under the confining pressures of 5,10 , 20 , and $30 \mathrm{MPa}$, the energy proportion (for example, the DE proportion) evolution was similar to the whole axial stressstrain curves, which could be divided into five stages (see Figure 8):

(i) Decreased suddenly (stage I)

(ii) Decreased nonlinearly (stage II)

(iii) Decreased approximately linearly (stage III)

(iv) Reached the minimum value and increased gradually (stage IV)

(v) Increased suddenly and leveled off (stage V)

In contrast, the evolution of the ESE proportion was in the opposite direction (see Figure 8). 


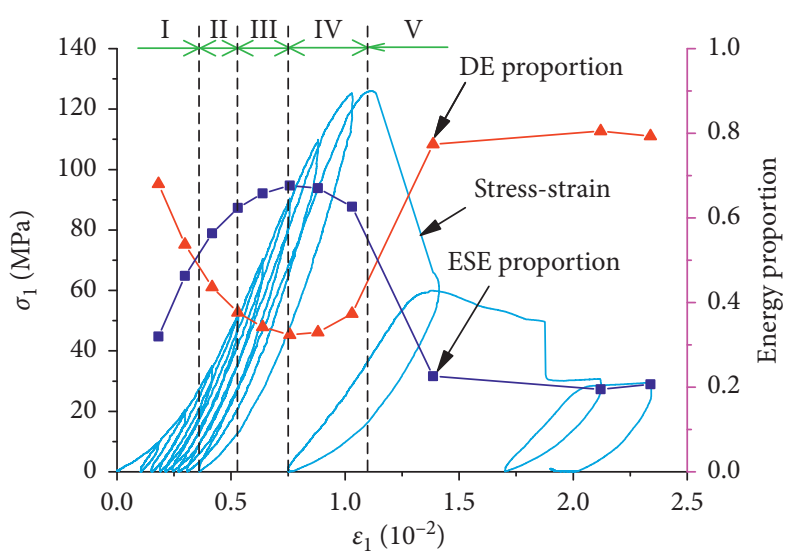

(a)

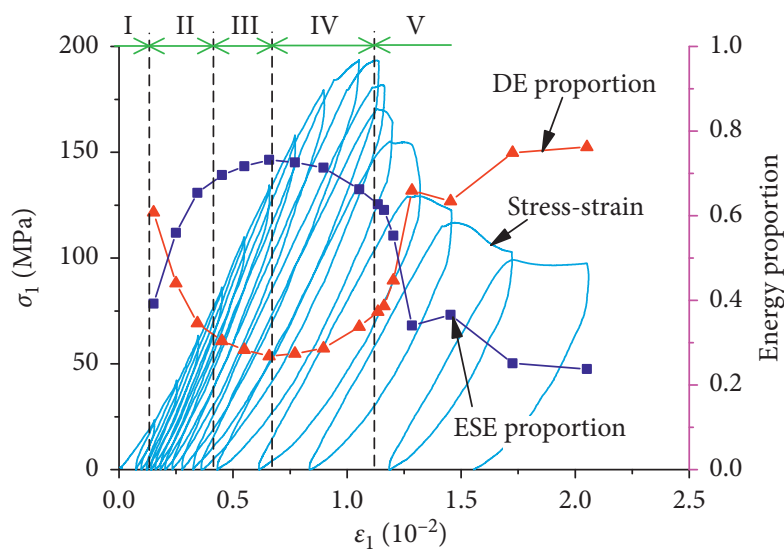

(c)

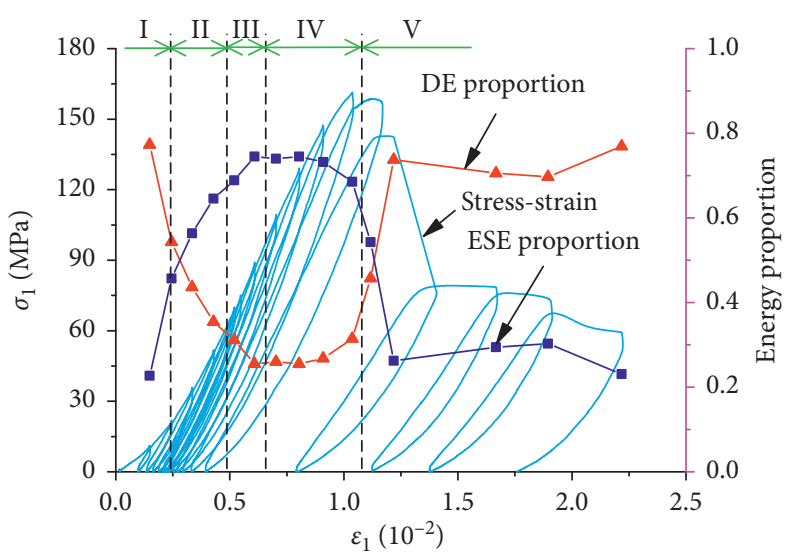

(b)

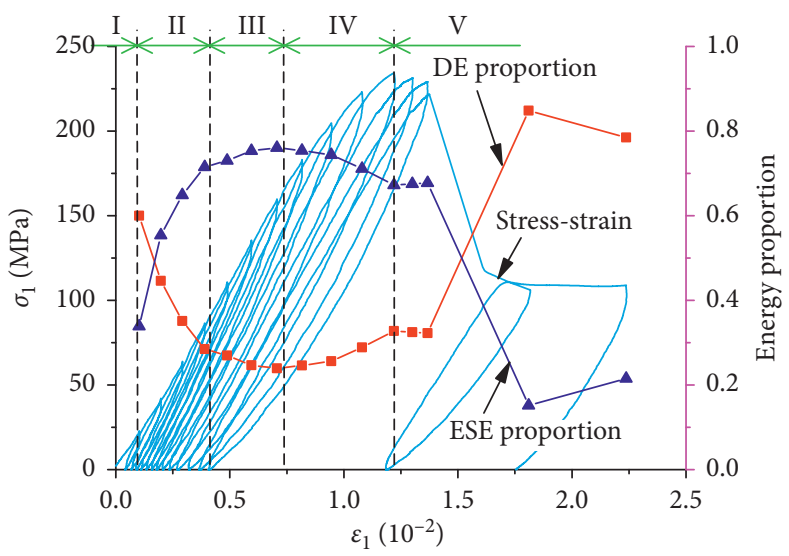

(d)

FIGURE 8: Energy proportion-strain curves with confining pressures of $5 \mathrm{MPa}$ (a), $10 \mathrm{MPa}$ (b), $20 \mathrm{MPa}$ (c), and $30 \mathrm{MPa}$ (d).

4.3. Proposed New Method. As previously mentioned, corresponding to the stages of the whole axial stress-strain curves during the cyclic loading-unloading triaxial compression tests, the energy proportion evolved obviously at each stage. Based on this, considering geotechnical engineering focused on the rock damage, we proposed a new method, energy proportion method (EPM), for determining characteristic stress during rock damage evolution using the DE proportion curves:

(i) Specimen preparation: rock samples are selected on-site, and standard specimens are produced by the ISRM-suggested method.

(ii) Test procedure: conventional triaxial compression tests are performed to determine the TCS; cyclic loading-unloading triaxial compression tests are performed with the unloading points which normalized to TCS varying from $0.1,0.2,0.3,0.4,0.5$, $0.6,0.7,0.8$, to 0.9 (or the hierarchical interval is reduced moderately to improve the accuracy).

(iii) Calculation: energy density is calculated (the TAE and the ESE) during a single cyclic loading using the area integral method by MATLAB, and then the DE proportion is calculated. (iv) Plot: the DE proportion-strain curves are drawn on the axial stress-strain curves during the cyclic loading-unloading triaxial compression tests.

(v) Determination (taking the confining pressures of 5 and $20 \mathrm{MPa}$ as an example (Figure 9)): firstly, the minimum value of the DE proportion is found (the green point), the vertical line is drawn (the purple line) starting with the green point, and the $\sigma_{\mathrm{cd}}$ contact with the axial stress-strain curve is determined; then, the tangent line is drawn starting with the green point (the blue line) and the $\sigma_{\mathrm{ci}}$ contact with the axial stress-strain curve is determined where the DE proportion deviated from linearity (the yellow point); and finally, the tangent is drawn starting with the yellow point (the black line) and the $\sigma_{\mathrm{cc}}$ where the axial stress deviated from linearity is determined. This could be concluded as "two points and three lines."

4.4. EPM: Application and Verification. We determined characteristic stress of sandstone specimens during damage evolution under the confining pressures of $5,10,20$, and $30 \mathrm{MPa}$. The determination process is shown in Figure 9 


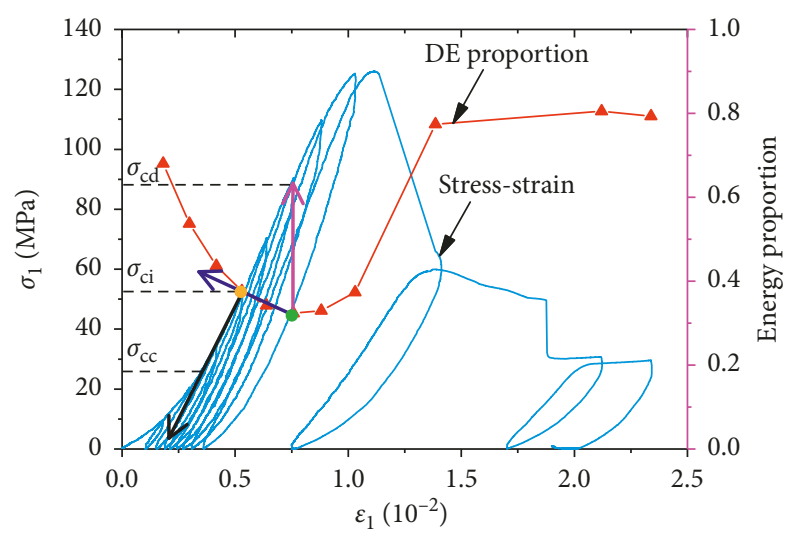

(a)

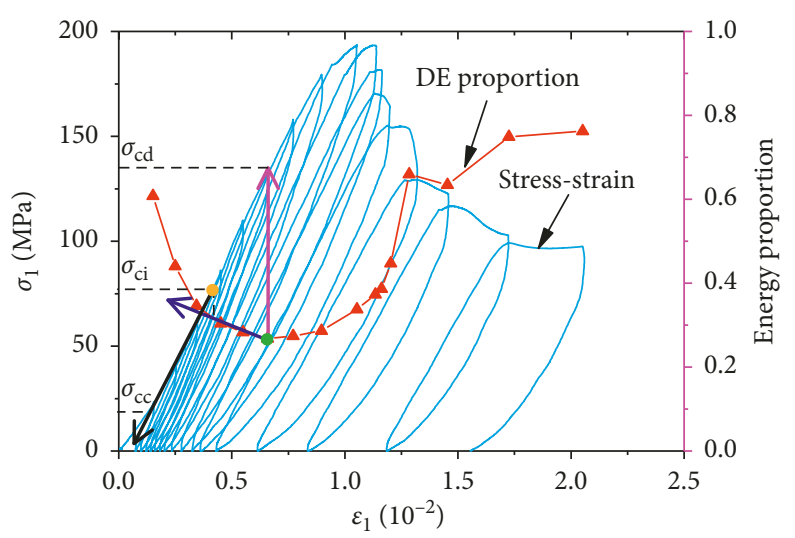

(b)

Figure 9: Determination process of characteristic stress by EPM with the confining pressures of $5 \mathrm{MPa}$ (a) and $20 \mathrm{MPa}$ (b).

TABLE 1: Comparison of characteristic stress determined by the three methods.

\begin{tabular}{|c|c|c|c|c|c|c|c|c|c|c|c|c|c|c|c|c|}
\hline \multirow{3}{*}{$\begin{array}{l}\text { Confining } \\
\text { stress (MPa) }\end{array}$} & \multirow{3}{*}{$\begin{array}{c}\text { Peak stress } \\
\sigma_{\mathrm{p}}(\mathrm{MPa})\end{array}$} & \multicolumn{6}{|c|}{ Characteristic stress $(\mathrm{MPa})$} & \multirow{2}{*}{\multicolumn{3}{|c|}{$\begin{array}{l}\text { Difference } \\
(\mathrm{MPa})\end{array}$}} & \multicolumn{6}{|c|}{ Ratio of characteristic stress to $\sigma_{\mathrm{ci}}(\%)$} \\
\hline & & \multicolumn{3}{|c|}{ EPM } & \multicolumn{2}{|c|}{ LSM } & \multirow{2}{*}{$\begin{array}{c}\mathrm{VSM} \\
\sigma_{\mathrm{cd}}\end{array}$} & & & & \multicolumn{3}{|c|}{$\mathrm{EPM}$} & \multicolumn{2}{|c|}{ LSM } & \multirow{2}{*}{$\begin{array}{l}\mathrm{VSM} \\
\sigma_{\mathrm{cd}} / \sigma_{\mathrm{p}}\end{array}$} \\
\hline & & $\sigma_{\mathrm{cc}}$ & $\sigma_{\mathrm{ci}}$ & $\sigma_{\mathrm{cd}}$ & $\sigma_{\mathrm{cc}}$ & $\sigma_{\mathrm{ci}}$ & & $\sigma_{\mathrm{cc}}$ & $\sigma_{\mathrm{ci}}$ & $\sigma_{\mathrm{cd}}$ & $\sigma_{\mathrm{cc}} / \sigma_{\mathrm{p}}$ & $\sigma_{\mathrm{ci}} / \sigma_{\mathrm{p}}$ & $\sigma_{\mathrm{cd}} / \sigma_{\mathrm{p}}$ & $\sigma_{\mathrm{cc}} / \sigma_{\mathrm{p}}$ & $\sigma_{\mathrm{ci}} / \sigma_{\mathrm{p}}$ & \\
\hline 5 & & 26.80 & 52.15 & 87.80 & & 52.25 & & 1.60 & & -2.0 & 21.27 & & & & & 68.10 \\
\hline 10 & & & & & & & & & & & & & & & & \\
\hline 20 & & 18.70 & 77.00 & 35.50 & 21.82 & 77.50 & 137.00 & 3.12 & 0.50 & 1.5 & 9.64 & 39.69 & & 11.25 & & 70.62 \\
\hline 30 & 34.00 & 12.15 & 90.00 & 165.50 & 15.80 & 91.00 & 170.00 & 3.65 & 1.00 & 4.50 & 5.19 & 38.46 & 70.73 & 6.75 & 38.89 & 72.65 \\
\hline Mean & - & - & - & - & - & - & - & 2.61 & 1.05 & 2.25 & - & 39.68 & 68.19 & - & 40.28 & 69.25 \\
\hline
\end{tabular}

(only the confining pressures of 5 and $20 \mathrm{MPa}$ are shown), and the results are shown in Table 1.

In Table 1, the characteristic stress was determined by EPM: with the confining pressure increase, the $\sigma_{\mathrm{cc}}$ decreased and the $\sigma_{\mathrm{ci}}$ and the $\sigma_{\mathrm{cd}}$ increased, whereas the ratio of characteristic stress to peak stress was different; the confining pressure had a significant effect on $\sigma_{\mathrm{cc}} / \sigma_{\mathrm{p}}$ which decreased with the confining pressure increase, while the $\sigma_{\mathrm{ci}} /$ $\sigma_{\mathrm{p}}$ and the $\sigma_{\mathrm{cd}} / \sigma_{\mathrm{p}}$ barely changed. Under the confining pressures of $5,10,20$, and $30 \mathrm{MPa}$, the $\sigma_{\mathrm{ci}} / \sigma_{\mathrm{p}}$ was $41.39 \%$, $39.19 \%, 39.69 \%$, and $38.46 \%$, with an average of $39.68 \%$, and the $\sigma_{\mathrm{cd}} / \sigma_{\mathrm{p}}$ was $69.68 \%, 62.50 \%, 69.85 \%$, and $70.73 \%$, with an average of $68.19 \%$; that is, under different confining pressures, the $\sigma_{\mathrm{cd}} / \sigma_{\mathrm{p}}$ was all about $40 \%$ and the $\sigma_{\mathrm{cd}} / \sigma_{\mathrm{p}}$ was all about $70 \%$. From an energetic standpoint, the confining pressure amplified the ability of rock specimens to store and dissipate energy, while the distribution proportion of energy almost unchanged.

For the memory function of the rock specimen, we drew the outer envelopes of the axial stress-lateral strain curves and the volumetric strain-axial strain curves which were obtained from the cyclic loading-unloading triaxial compression tests (see Figure 10). The lateral strain method (LSM) and the volumetric strain method (VSM) were chosen to verify the EPM. The determination process is shown in Figure 10 (taking the confining pressures of 5 and $20 \mathrm{MPa}$ for example): the start and the end of the linear region on the outer envelope of the lateral strain corresponded to the $\sigma_{\mathrm{cc}}$ and the $\sigma_{\mathrm{ci}}$, respectively, and the peak of volumetric strain corresponded to the $\sigma_{\mathrm{cd}}$ (see Table 1 ). For the changing trend of characteristic stress, the results determined by LSM and VSM were similar to those by EPM. For the difference of characteristic stress, the results determined by LSM and VSM were larger than those by EPM, with an average of $2.61 \mathrm{MPa}\left(\sigma_{\mathrm{cc}}\right), 1.05 \mathrm{MPa}\left(\sigma_{\mathrm{ci}}\right)$, and $2.25 \mathrm{MPa}\left(\sigma_{\mathrm{cd}}\right)$. For the ratio of characteristic stress to peak stress, the trend of $\sigma_{\mathrm{cc}} / \sigma_{\mathrm{p}}$ determined by LSM was similar to that by EPM, i.e., decreasing trend with the confining pressure increase; the $\sigma_{\mathrm{ci}} /$ $\sigma_{\mathrm{p}}$ was still about $40 \%$ determined by LSM, and the $\sigma_{\mathrm{cd}} / \sigma_{\mathrm{p}}$ was still about $70 \%$ determined by VSM.

Comparisons showed that the EPM was feasible. In practical applications, the DE proportion had clearer response to damage evolution, better coordination with damage evolution, and less subjective initiative, and the $\sigma_{\mathrm{cd}}$, $\sigma_{\mathrm{ci}}$, and $\sigma_{\mathrm{cc}}$ could be determined in turn by "two points and three lines" using the EPM.

\section{Equation of Damage Evolution}

The mechanical evolution of loaded rock specimens is a progressive damage. Research on damage evolution from an energetic standpoint contains mechanical processes, such as strength and deformation characteristics, so it can reveal the damage and failure mechanism of rock more essentially. Jin et al. [31] defined and calculated the damage variable from an energetic standpoint and researched the damage propagation law of rock materials. Zhao et al. [32] revised the damage variable, derived the relationship between dissipated 

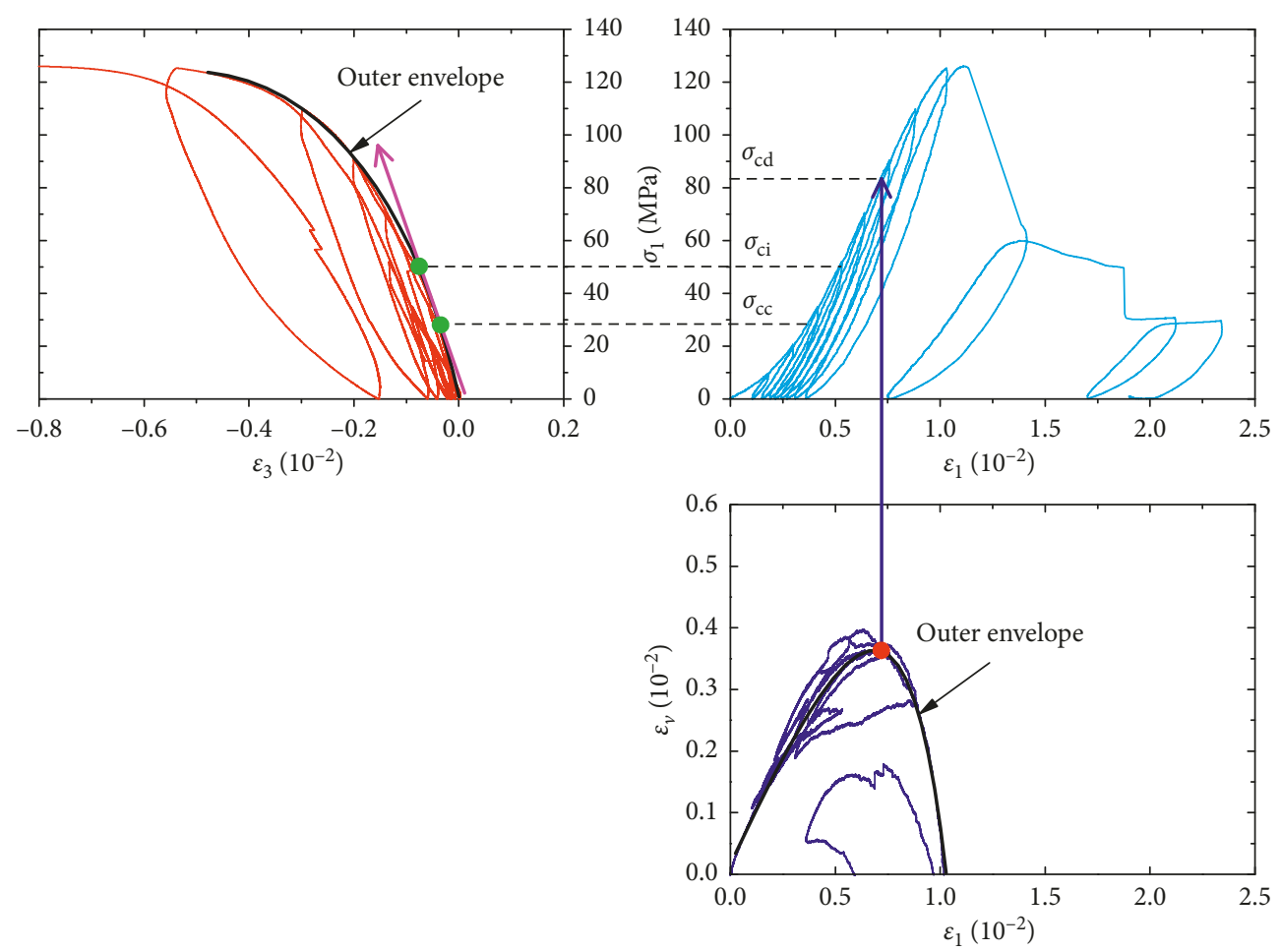

(a)
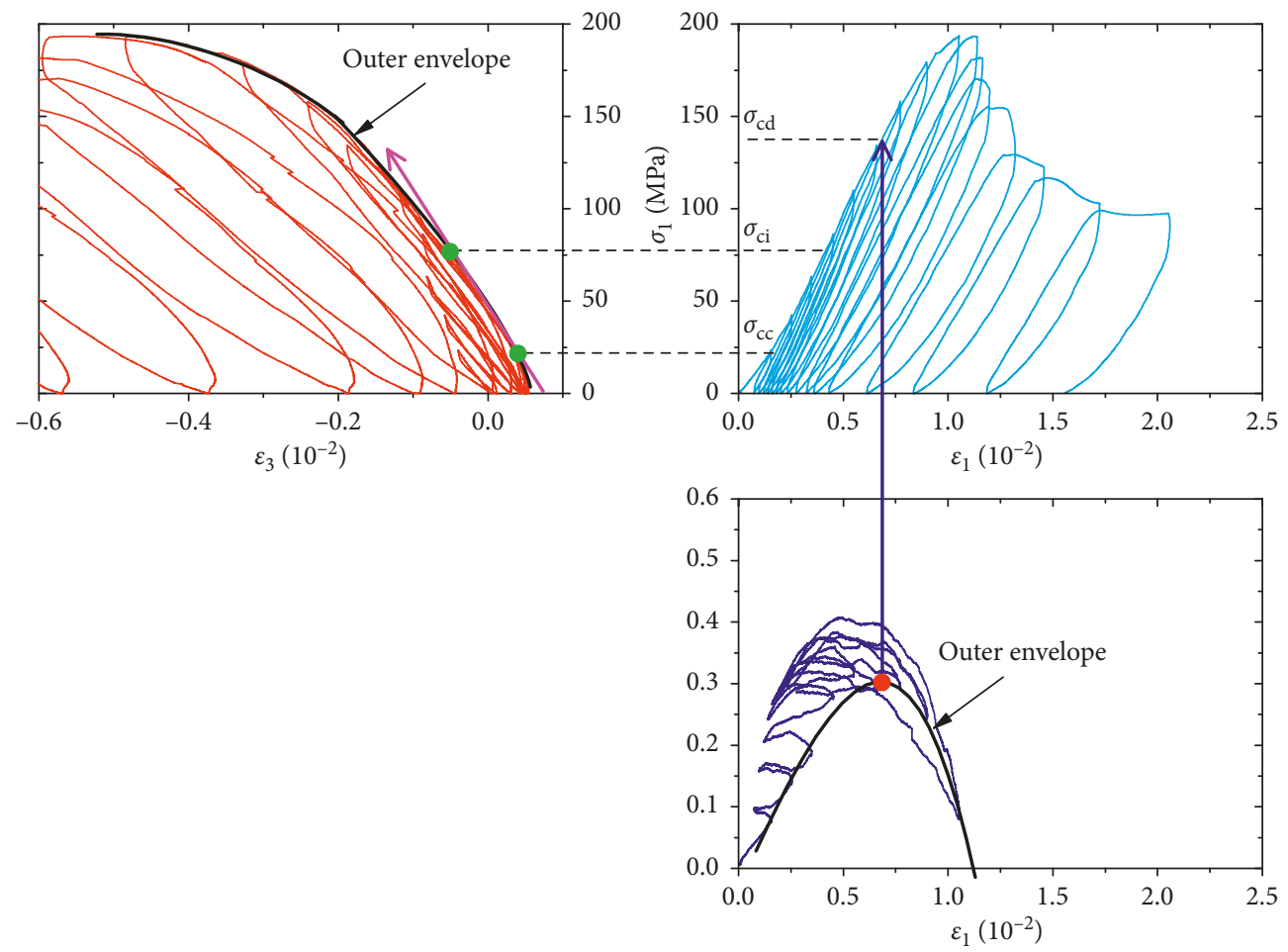

(b)

FIGURE 10: Determination process of characteristic stress by LSM and VSM with the confining pressures of $5 \mathrm{MPa}$ (a) and $20 \mathrm{MPa}$ (b). 
energy and damage variable, and then established the damage equation. Liu et al. [33] introduced the damage variable and compaction factor based on energy and revised the equation of damage evolution and verified it using experimental data. Li et al. [34] defined the damage variable and calculated damage modulus from an energetic standpoint and then analyzed damage modulus evolution with confining pressures. Moreover, the above research studies also showed that the energy proportion evolution could explain the deformation of loaded rock specimens. Based on this, we established the relationship between elastic modulus and $\mathrm{DE}$ proportion, fitted the mathematical expression of the DE proportion, and then derived the equation of damage evolution of loaded rock specimens.

Theevolution laws of elastic modulus which were illustrated in Section 3.2 were similar to the evolution laws of energy proportion illustrated in Section 4.2, so we defined the relationship between elastic modulus and $\mathrm{DE}$ proportion:

$$
E=a(1-\eta) E_{0},
$$

where $a$ is a scaling factor, greater than 1 , relating to the confining pressures, and $E_{0}$ is the maximum value of the elastic modulus at the linear-elastic deformation stage.

5.1. Equation of Energy Proportion. We fitted the DE proportion under confining pressures of $5,10,20$, and $30 \mathrm{MPa}$ (see Figure 11), and the fitting function and parameters are shown in Table 2. From the fitting curves, at the initial stage of DE proportion, i.e., the I, II, and III stages, the difference of $\mathrm{DE}$ proportion gradually decreased to be aligned at the same strain level, with the confining pressures of $5,10,20$, and $30 \mathrm{MPa}$, while the difference of DE proportion at the same strain level gradually increased at the IV stage and the previous $\mathrm{V}$ stage and decreased to be stable at the later stage of $\mathrm{V}$.

The meaning of fitting function and parameters is shown in Figure 12, and combined with the fitting curves in Figure 11, we concluded the following:

(i) $\eta_{0}$ is the maximum value of DE proportion at the $\mathrm{V}$ stage

(ii) $A$ is the difference of $\mathrm{DE}$ proportion between the minimum value at the III stage and the maximum value at the $\mathrm{V}$ stage

(iii) $\varepsilon_{c}$ is the axial strain corresponding to the minimum value of the DE proportion at the III stage

(iv) $w$ is the total axial strain corresponding to the III stage and IV stage of the DE proportion

From Table 2 , it is seen that the fitting parameters, like $\eta_{0}$ and $A$, almost did not change with the confining pressure change, as explained in Section 4.4 (the distribution proportion of energy in rock almost unchanged with the confining pressure); $\varepsilon_{c}$ and $w$ increased with the confining pressure increase, which also could be obtained in Figure 8.

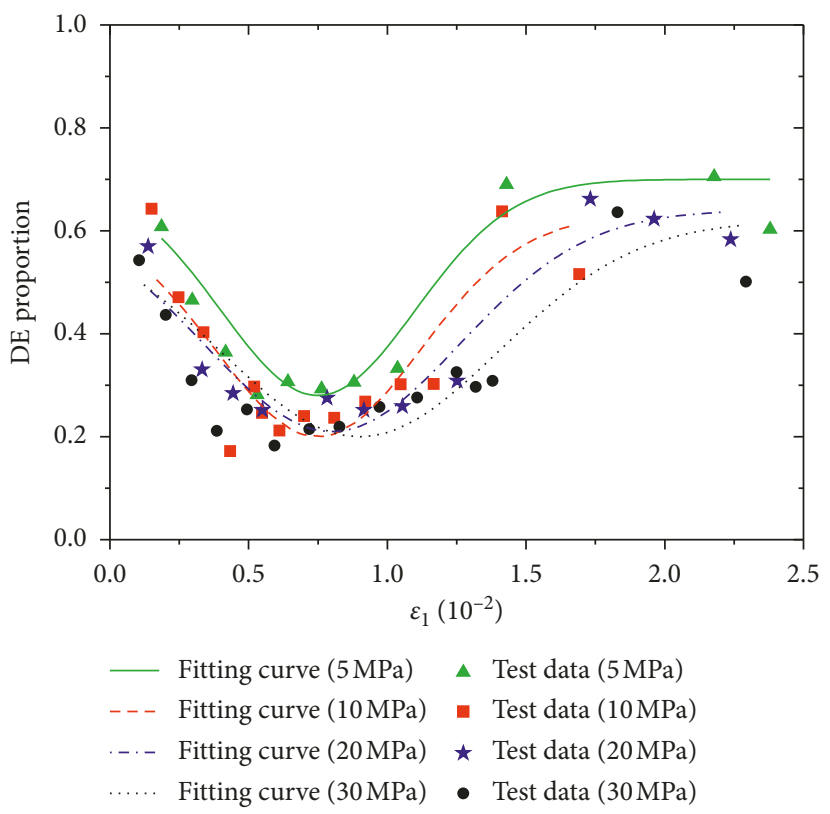

FIgUre 11: Experimental and fitting curves of DE proportion.

TABLE 2: Fitting function and parameters of DE proportion.

\begin{tabular}{lcccc}
\hline & \multicolumn{5}{c}{ Fitting function and parameters } \\
Confining stress (MPa) & \multicolumn{4}{c}{$\eta=\eta_{0}-A e^{-\left(\left(\varepsilon-\varepsilon_{c}\right)^{2} / 2 w^{2}\right)}$} \\
& $\eta_{0}$ & $A$ & $\varepsilon_{c}$ & $w$ \\
\hline 5 & 0.7 & 0.42 & 0.75 & 0.35 \\
10 & 0.63 & 0.43 & 0.75 & 0.37 \\
20 & 0.64 & 0.43 & 0.8 & 0.46 \\
30 & 0.62 & 0.42 & 0.9 & 0.5 \\
\hline
\end{tabular}

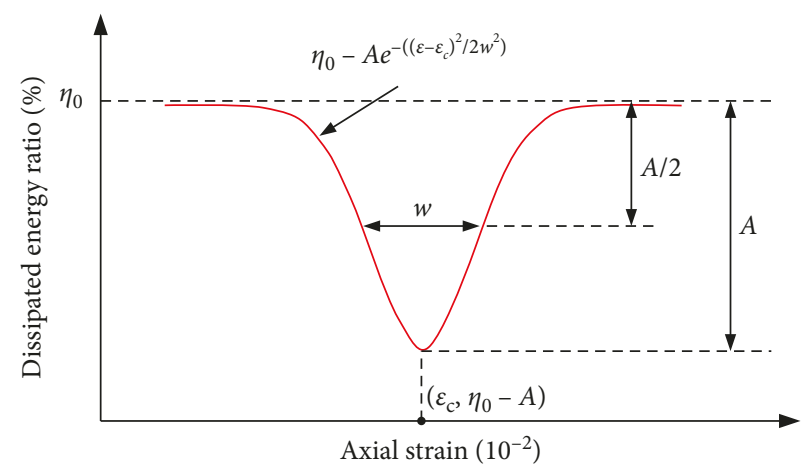

FIGURE 12: Meaning of the function image and the parameters of the DE proportion.

5.2. Constitutive Equation of Damage Evolution Based on Energy Proportion. In Figure 5, during the $i$-th cyclic loading, the total axial strain $\varepsilon_{i}$ contained the recoverable strain $\varepsilon_{i}^{e}$ and the residual strain $\varepsilon_{i}^{d}$ :

$$
\varepsilon_{i}=\varepsilon_{i}^{e}+\varepsilon_{i}^{d} .
$$




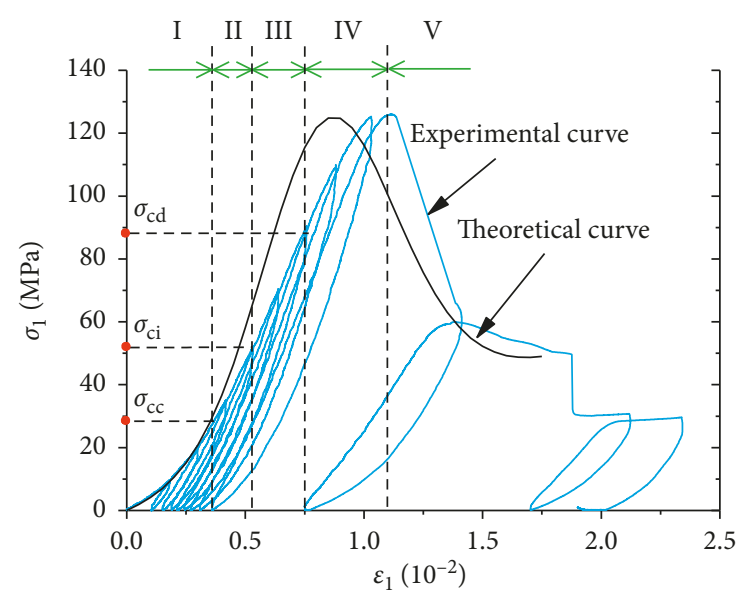

(a)

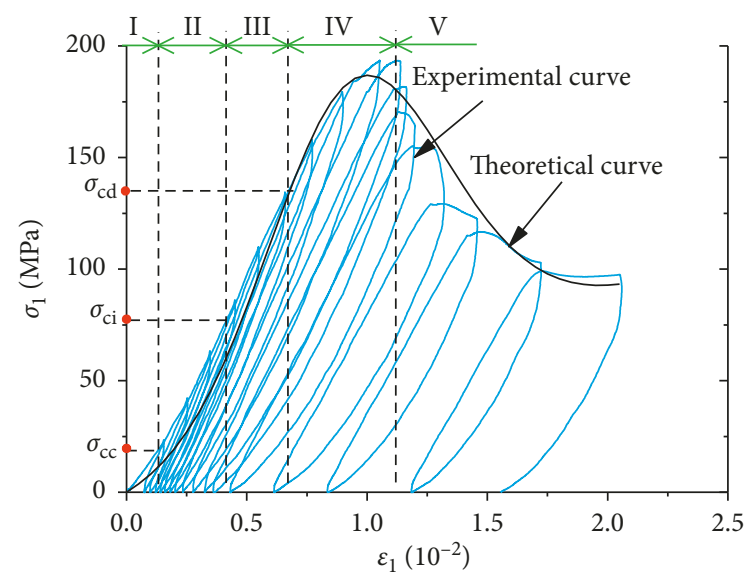

(c)

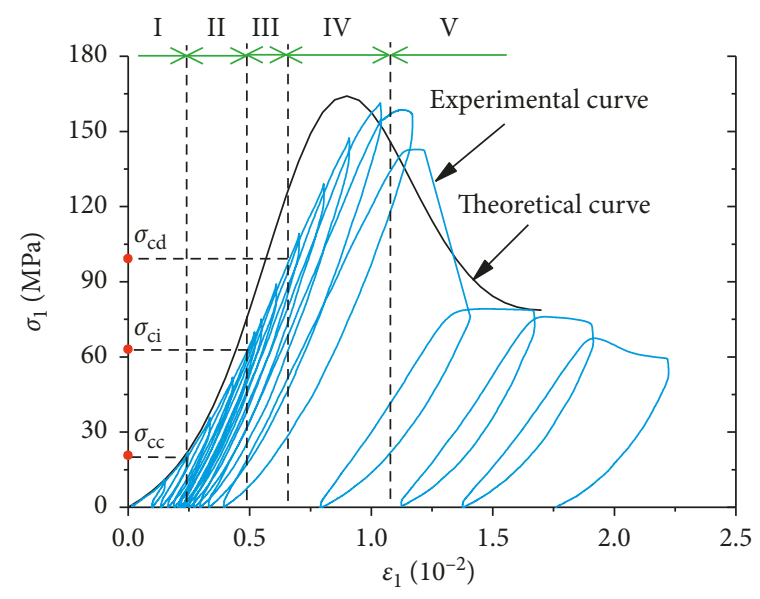

(b)

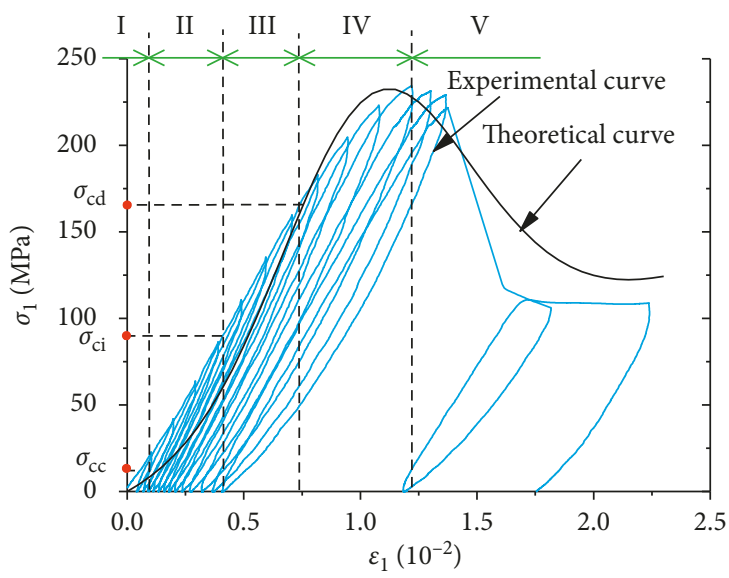

(d)

Figure 13: Theoretical stress-strain curves based on energy proportion with the confining pressures of $5 \mathrm{MPa}$ (a), $10 \mathrm{MPa}$ (b), $20 \mathrm{MPa}$ (c), and $30 \mathrm{MPa}(\mathrm{d})$.

By using formulas (2) and (3), the following relations were obtained approximately:

$$
\begin{aligned}
\varepsilon_{i}^{e} & =\left(1-\eta_{i}\right) \varepsilon_{i}, \\
\varepsilon_{i}^{d} & =\eta_{i} \varepsilon_{i} .
\end{aligned}
$$

The stress of loaded rock specimens contains the elastic part and damage part, which can be described by using the elastic part [35]:

$$
\sigma=E \varepsilon^{e} .
$$

Taking $E$ and $\varepsilon^{e}$ which contain damage parameter (the $\mathrm{DE}$ proportion), the stress is

$$
\sigma=a(1-\eta)^{2} E_{0} \varepsilon=a\left(1-\left(\eta_{0}-A e^{-\left(\varepsilon-\varepsilon_{c}\right)^{2} / 2 w^{2}}\right)\right)^{2} E_{0} \varepsilon .
$$

This equation could describe the axial stress-strain curves, and the values of $a$ were $1.65,1.48,1.38$, and 1.28. Then, we obtained the theoretical axial stress-strain curves under the confining pressures of $5,10,20$, and $30 \mathrm{MPa}$, respectively (see Figure 13).

As shown in Figure 13, fitting function for the theoretical curves described the experimental curves. But some of the shortcomings existed corresponded to the stages of the experimental curves which were divided by the DE proportion (see Figures 8 and 13): At the I stage, the theoretical curves coincided with the experimental curves under the confining pressures of 5 and $10 \mathrm{MPa}$, while they gradually deviated and depressed with the confining pressure increase. They had an upward departure with low confining pressures at the II stage, while downward deviation with the confining pressure increase, and the deviation degree was minimum with the confining pressure of $10 \mathrm{MPa}$. They also had an upward departure with low confining pressures at the III stage, but downward deviation with the confining pressure increase, and the deviation degree was minimum with the confining pressure of $20 \mathrm{MPa}$. They had an upward departure at the IV stage, while the deviation degree gradually decreased with the confining pressure increase. At the IV stage, the deviation 
degree was minimum with the confining pressure of $20 \mathrm{MPa}$.

\section{Conclusion}

The objective of this paper is to propose a new method for determining characteristic stress and to establish a constitutive equation for damage evolution of sandstone from an energetic standpoint. The cyclic loading-unloading triaxial compression tests which were implemented with confining pressures of $5,10,20$, and $30 \mathrm{MPa}$ revealed that the energy evolution corresponded to the damage deformation of rock specimens, and the energy transformation could describe crack closure, initiation, growth, and coalescence under the loading process. Furthermore, the parameter of energy proportion was defined. Taking the DE proportion as an example, it was divided into five stages corresponding to the five stages of the whole stress-strain curve. The EPM for determining characteristic stress was proposed and was used to determine the characteristic stress of sandstone during the cyclic loading-unloading triaxial compression tests. The results showed that, with the confining pressure increase, the $\sigma_{\mathrm{cc}}$ decreased, while the $\sigma_{\mathrm{ci}}$ and the $\sigma_{\mathrm{cd}}$ increased; under different confining pressures, the $\sigma_{\mathrm{cc}} / \sigma_{\mathrm{p}}$ decreased, the $\sigma_{\mathrm{cd}} /$ $\sigma_{\mathrm{p}}$ was about $40 \%$, and the $\sigma_{\mathrm{cd}} / \sigma_{\mathrm{p}}$ was about $70 \%$ because the distribution proportion of energy in rock specimens almost was unchanged with different confining pressures. Also, the results were verified by LSM and VSM: for the difference of characteristic stress, the results determined by LSM and VSM were larger than those by ERM, while they were in the acceptable error range; for the ratio of characteristic stress to peak stress, the trend of $\sigma_{\mathrm{cc}} / \sigma_{\mathrm{p}}$ determined by LSM was similar to that by ERM, the $\sigma_{\mathrm{ci}} / \sigma_{\mathrm{p}}$ was still about $40 \%$ determined by LSM, and the $\sigma_{\mathrm{cd}} / \sigma_{\mathrm{p}}$ was still about $70 \%$ determined by VSM.

Based on the analysis of material parameter evolution, the relationship between elastic modulus and DE proportion was defined. The DE proportions fitted under confining pressures, and the fitting function and parameters had certain significance. Furthermore, the equation of damage evolution based on energy proportion was established. According to the five stages of DE proportion evolution, the theoretical curve and experimental curve of the damage evolution equation were compared, and then the rationality of the damage constitutive theory established by DE proportion evolution was verified.

\section{Data Availability}

The data used to support the findings of this study are available from the corresponding author upon request.

\section{Conflicts of Interest}

The authors declare that they have no conflicts of interest.

\section{Acknowledgments}

This study was supported by the National Natural Science Foundation of China (nos. 50904071 and 51274207).

\section{References}

[1] D. Lockner, "The role of acoustic emission in the study of rock fracture," International Journal of Rock Mechanics and Mining Sciences \& Geomechanics Abstracts, vol. 7, no. 30, pp. 883899, 1993.

[2] C. Martin, R. S. Read, and J. B. Martino, "Observations of brittle failure around a circular test tunnel," International Journal of Rock Mechanics and Mining Science \& Geomechanics Abstracts, vol. 34, no. 7, pp. 1065-1073, 1997.

[3] M. S. Diederichs, "Manuel rocha medal recipient rock fracture and collapse under low confinement conditions," Rock Mechanics and Rock Engineering, vol. 36, no. 5, pp. 339-381, 2003.

[4] W. F. Brace, B. W. Paulding, and C. H. Scholz, "Dilatancy in the fracture of crystalline rocks," Journal of Geophysical Research, vol. 16, no. 71, pp. 3939-3953, 1966.

[5] C. D. Martin and N. A. Chandler, "The progressive fracture of Lac du Bonnet granite," International Journal of Rock Mechanics and Mining Sciences \& Geomechanics Abstracts, vol. 31, no. 6, pp. 643-659, 1994.

[6] E. Eberhardt, D. Stead, and B. Stimpson, "Identifying crack initiation and propagation thresholds in brittle rock," $\mathrm{Ca}$ nadian Geotechnical Journal, vol. 2, no. 35, pp. 222-233, 1998.

[7] M. S. Diederichs, P. K. Kaiser, and E. Eberhardt, "Damage initiation and propagation in hard rock during tunnelling and the influence of near-face stress rotation," International Journal of Rock Mechanics and Mining Sciences, vol. 41, no. 5, pp. 785-812, 2004.

[8] M. Cai, P. K. Kaiser, Y. Tasaka, T. Maejima, H. Morioka, and M. Minami, "Generalized crack initiation and crack damage stress thresholds of brittle rock masses near underground excavations," International Journal of Rock Mechanics and Mining Sciences, vol. 41, no. 5, pp. 833-847, 2004.

[9] E. Hoek and E. T. Brown, Underground Excavations in Rock, The Institution of Mining and Metallurgy, London, UK, 1980.

[10] C. D. Martin and R. Christiansson, "Estimating the potential for spalling around a deep nuclear waste repository in crystalline rock," International Journal of Rock Mechanics and Mining Sciences, vol. 46, no. 2, pp. 219-228, 2009.

[11] J. C. Andersson, C. D. Martin, and H. Stille, “The Äspö pillar stability experiment: part I-experiment design," International Journal of Rock Mechanics and Mining Sciences, vol. 46, no. 5, pp. 865-878, 2009.

[12] E. Z. Lajtal and V. N. Lajtal, "The evolution of brittle fracture in rocks," Journal of the Geological Society of London, vol. 130, no. 1, pp. 1-16, 1974.

[13] M. Nicksiar and C. D. Martin, "Evaluation of methods for determining crack initiation in compression tests on lowporosity rocks," Rock Mechanics and Rock Engineering, vol. 45, no. 4, pp. 607-617, 2012.

[14] E. Eberhardt, Brittle Rock Fracture and Progressive Damage in Uniaxial Compression, University of Saskatchewan, Saskatoon, SK, Canada, 1998.

[15] X. G. Zhao, M. Cai, J. Wang, and L. K. Ma, "Damage stress and acoustic emission characteristics of the Beishan granite," International Journal of Rock Mechanics and Mining Sciences, vol. 64, pp. 258-269, 2013.

[16] L. Xue, S. Qin, Q. Sun, Y. Wang, L. M. Lee, and W. Li, “A study on crack damage stress thresholds of different rock types based on uniaxial compression tests," Rock Mechanics and Rock Engineering, vol. 47, no. 4, pp. 1183-1195, 2014.

[17] M. Nicksiar and C. D. Martin, "Evaluation of methods for determining crack initiation in compression tests on low- 
porosity rocks," Rock Mechanics and Rock Engineering, vol. 45, no. 4, pp. 607-617, 2012.

[18] P. F. Li, X. G. Zhao, and M. F. Cai, "Discussion on approaches to identifying cracking initiation stress of rocks under compression condition: a case study of Tianhu granodiorite in Xinjiang autonomous region," Rock and Soil Mechanics, vol. 36, no. 8, pp. 2323-2331, 2015.

[19] T. Wen, H. Tang, J. Ma, and Y. Wang, "Evaluation of methods for determining crack initiation stress under compression," Engineering Geology, vol. 235, pp. 81-97, 2018.

[20] H. P. Xie, R. D. Peng, and Y. Ju, "Energy dissipation of rock deformation and fracture," Chinese Journal of Rock Mechanics and Engineering, no. 2, pp. 3565-3570, 2004.

[21] H. Xie, L. Li, Y. Ju, R. Peng, and Y. Yang, "Energy analysis for damage and catastrophic failure of rocks," Science China Technological Sciences, vol. 54, no. S1, pp. 199-209, 2011.

[22] Z. Z. Zhang and F. Gao, "Experimental research on energy evolution of Red Sandstone samples under uniaxial compression," Chinese Journal of Rock Mechanics and Engineering, vol. 31, no. 5, pp. 953-962, 2012.

[23] H. F. Deng, Y. Hu, J. L. Li et al., "The evolution of sandstone energy dissipation under cyclic loading and unloading," Chinese Journal of Rock Mechanics and Engineering, vol. 35, no. 1, pp. 2869-2875, 2016.

[24] Q. Meng, M. Zhang, Z. Zhang et al., "Experimental research on rock energy evolution under uniaxial cyclic loading and unloading compression," Geotechnical Testing Journal, vol. 41, no. 4, pp. 717-729, 2017.

[25] G. Hu, Q. H. Zhao, Y. S. He et al., "Elastic modulus's evolution law of plagiogranite under cyclic loading," Journal of Engineering Geology, vol. 24, no. 5, pp. 881-890, 2016.

[26] Y. I. Song, Y. D. Jiang, S. P. Ma et al., "Evolution of deformation fields and energy in whole process of rock failure," Rock and Solid Mechanics, vol. 33, no. 5, pp. 1352-1356, 2012.

[27] Z. Z. Zhang, Energy Evolution Mechanism during Rock Deformation and Failure, China University of Mining and Technology, Xuzhou, China, 2013.

[28] Y. P. Qin, J. F. Zhang, and L. Wang, "Preliminary discussion on theoretical model of rock damage mechanics," Chinese Journal of Rock Mechanics and Engineering, vol. 22, no. 4, pp. 646-650, 2003.

[29] X. Y. Wang, H. W. Zhou, J. C. Zhong et al., "Study on energy evolution and permeability characteristics of damage of deep coal under triaxial cyclic loading and unloading conditions," Chinese Journal of Rock Mechanics and Engineering, vol. 37, no. 9, pp. 1-10, 2018.

[30] J. Ning, J. Wang, J. Jiang, S. Hu, L. Jiang, and X. Liu, "Estimation of crack initiation and propagation thresholds of confined brittle coal specimens based on energy dissipation theory," Rock Mechanics and Rock Engineering, vol. 51, no. 1, pp. 119-134, 2018.

[31] F. N. Jin, M. R. Jiang, and X. L. Gao, "Defining damage variable based on energy dissipation," Chinese Journal of Rock Mechanics and Engineering, vol. 23, no. 12, pp. 1976-1980, 2004.

[32] C. Zhao, K. Wu, S. C. Li et al., "Energy characteristics and damage deformation of rock subjected to cyclic loading," Chinese Journal of Geotechnical Engineering, vol. 35, no. 5, pp. 890-896, 2013.

[33] X. S. Liu, J. G. Ning, Y. L. Tan, and Q. H. Gu, "Damage constitutive model based on energy dissipation for intact rock subjected to cyclic loading," International Journal of Rock Mechanics and Mining Sciences, vol. 85, no. 3, pp. 27-32, 2016.
[34] B. Li, W. Xiao, and H. W. Wang, "Analysis of damage modulus of rock," China Earthquake Journal, vol. 40, no. 2, pp. 384-388, 2018.

[35] X. B. Yang, Y. P. Qin, and F. Ye, "Damage constitutive relation of sandstone considering residual stress," Journal of China Coal Society, vol. 40, no. 12, pp. 2807-2812, 2015. 


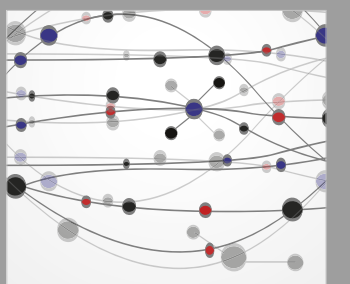

The Scientific World Journal
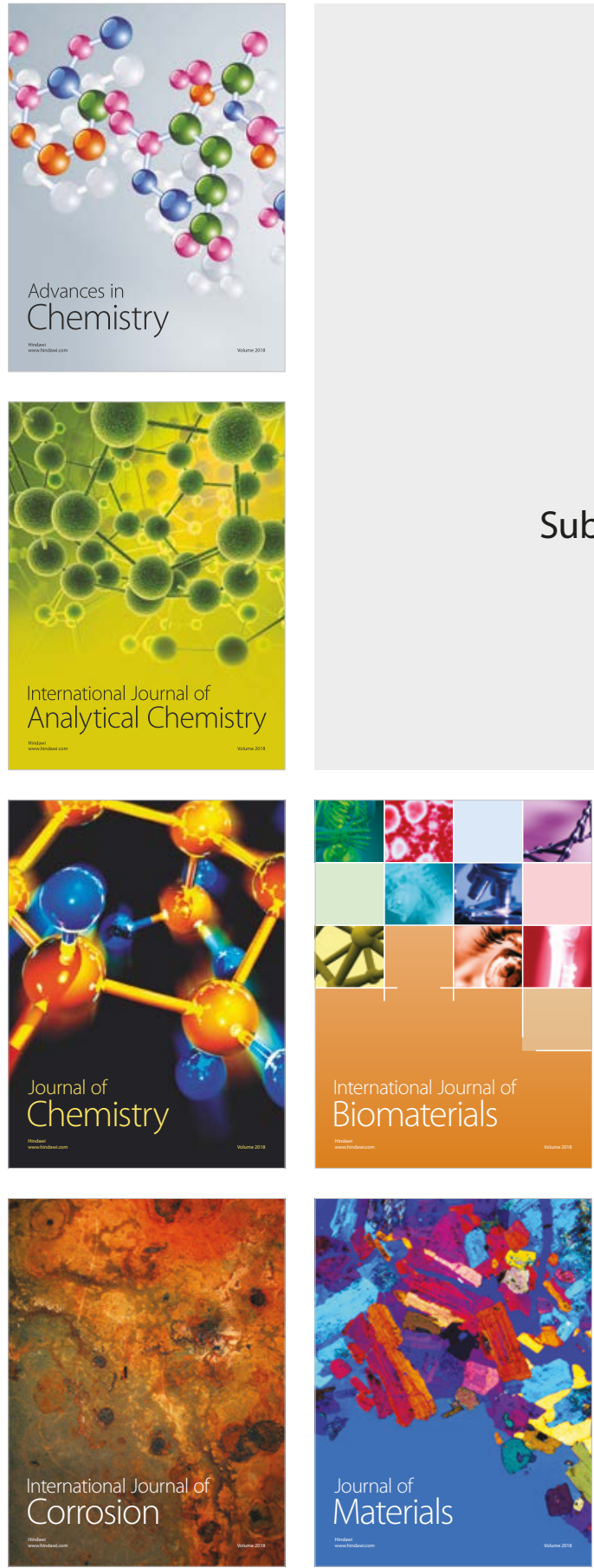

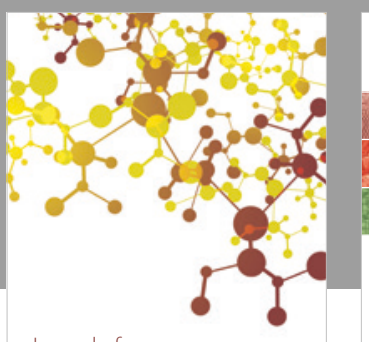

Journal of

Applied Chemistry
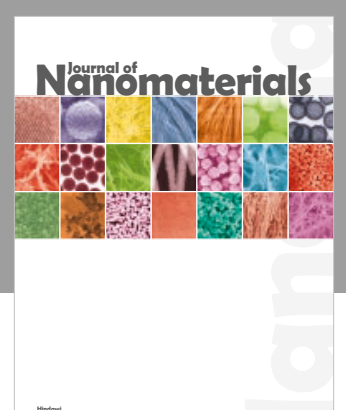

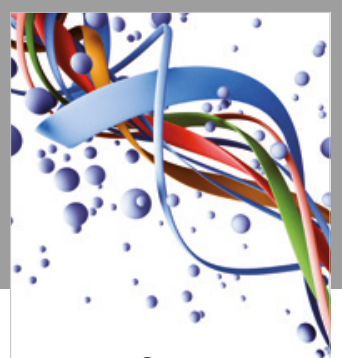

Scientifica

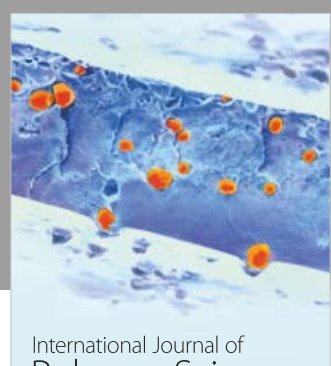

Polymer Science

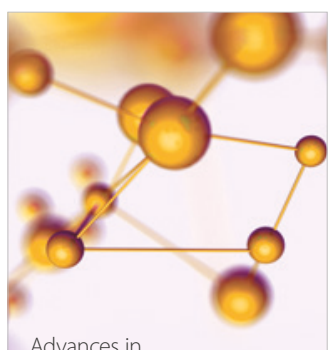

Physical Chemistry
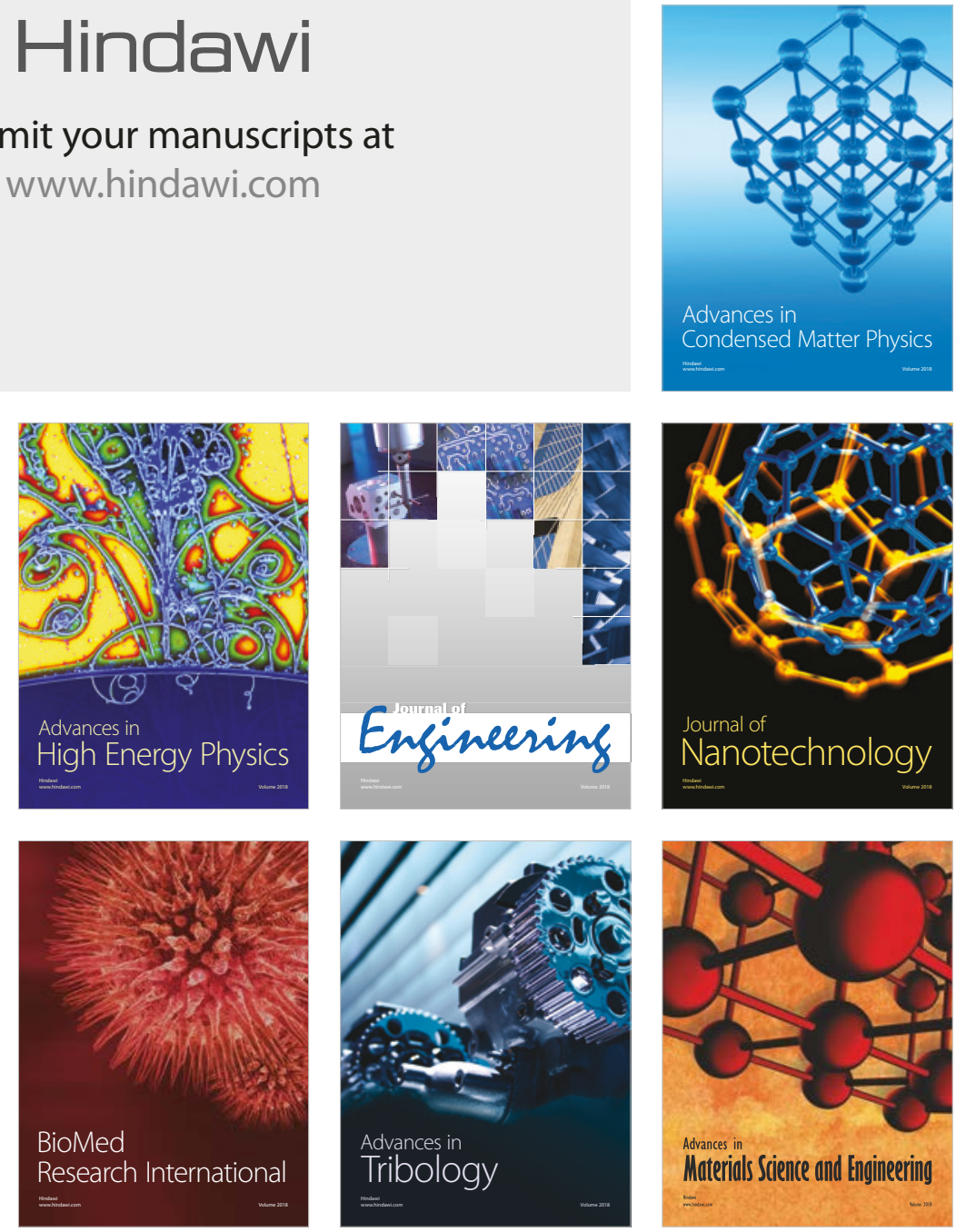